\title{
A Giant Thrombosed Intracavernous Carotid Aneurysm: A Case Report
} Soufiane Belabbes ${ }^{1 *}$, Taoufik Africha ${ }^{1}$, Brahim Zinoun ${ }^{1}$, Jamal El Fenni ${ }^{2}$, Issam En-Nafaa ${ }^{2}$

${ }^{1}$ Radiology Department, Moulay Ismail Military Hospital, Meknès, Morocco

${ }^{2}$ Radiology Departments, Military Teaching Hospital Mohammed V, Morocco

DOI: $\underline{10.36347 / \text { sjmcr.2020.v08i05.002 }}$

| Received: 25.04.2020 | Accepted: 03.05.2020 | Published: 06.05.2020

*Corresponding author: Soufiane Belabbes

Abstract

Case Report

Aneurysm of intracranial carotid artery is relatively rare and tends to be asymptomatic. However, as such an aneurysm increases in size, it can causes cavernous sinus syndrome resulting from a compressive mechanism. We report the case of a 38-year-old woman who presented with a rapid onset of diplopia, right palpebral ptosis and headache. A brain magnetic resonance imaging (MRI) revealed a right-sided partially thrombosed giant intracavernous aneurysm measuring $38 \mathrm{~mm}$ in diameter. No evidence of intracavernous of subarachnoid hemorrhage was observed. The patient was referred to neurosurgery department where an endovascular approach was performed.

Keywords: Internal carotid, intracavernous, aneurysm, thrombosis, imaging.

Copyright @ 2020: This is an open-access article distributed under the terms of the Creative Commons Attribution license which permits unrestricted use, distribution, and reproduction in any medium for non-commercial use (NonCommercial, or CC-BY-NC) provided the original author and source are credited.

\section{INTRODUCTION}

Intracranial artery aneurysms are found in 5\% of the general population, and show a slight female predominance [1]. Intracavernous carotid artery aneurysms (ICCA) represent approximately 3-5\% of all intracranial aneurysms and account for $15 \%$ of all internal carotid aneurysms. They can arise from any segment of cavernous carotid artery, but most commonly are originated in the horizontal segment [2]. In contrast to the intracranial supraclinoidal aneurysms, ruptures and subarachnoid hemorrhages very seldom occur and diagnosis is most often made based on compressive cavernous sinus symptoms [3]. As neuroimaging techniques have become more sophisticated, the diagnosis of cavernous aneurysms has increased markedly and about a third of these lesions are asymptomatic at diagnosis.

\section{CASE RePORT}

38-year-old woman, with no particular pathological antecedents, presented with a rapid onset of diplopia and a right palpebral ptosis associated with tension headaches and three episodes of vomiting. Clinical examination showed a complete oculomotor plasy and partial abducens deficit on the right side. Other cranial nerves were intact. Visual acuity was 10/10. With regard to the clinical findings, magnetic resonance imaging (MRI) of the brain was scheduled. Coronal and axial T2 weighted images demonstrated a right intracavernous heterogeneously masse measuring
$38 \mathrm{~mm}$ on diameter (Figure 1), and partially enhanced on $\mathrm{T} 1$ weighted image indicating a giant intracavernous partially thrombosed carotid aneurysm (Figure 2). No evidence of intracavernous or subarachnoid hemorrhage was found on FLAIR images (Figure 1). The patient was referred to neurosurgery department where an endovascular approach was performed

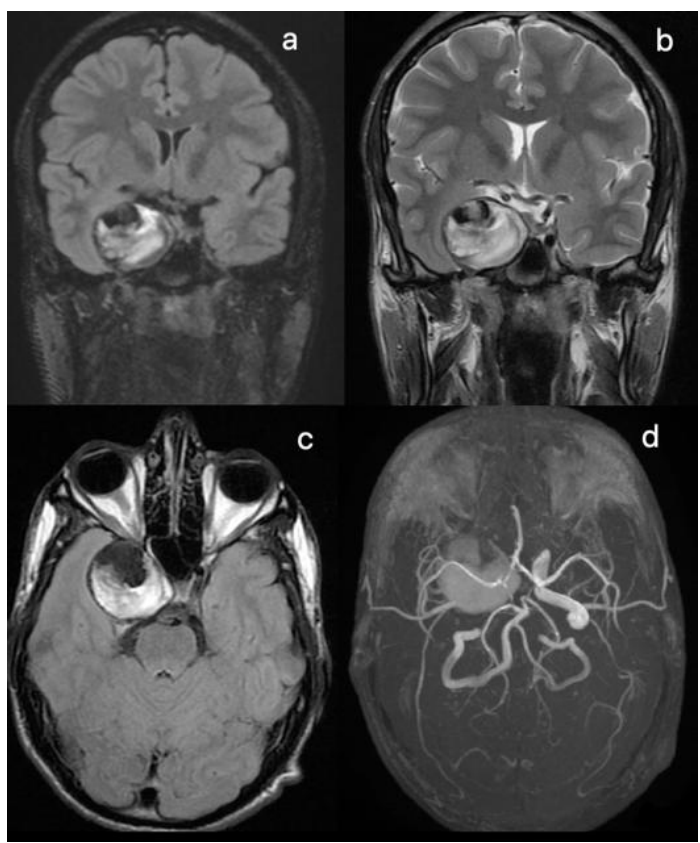

Fig-1: Cerebral MRI, coronal(a) and axial (c) Flair, coronal T2 (b), and 3DTOF, right intracavernous aneurysm with flow void containing a partial thrombosis (high signal on T2, and Flair) 


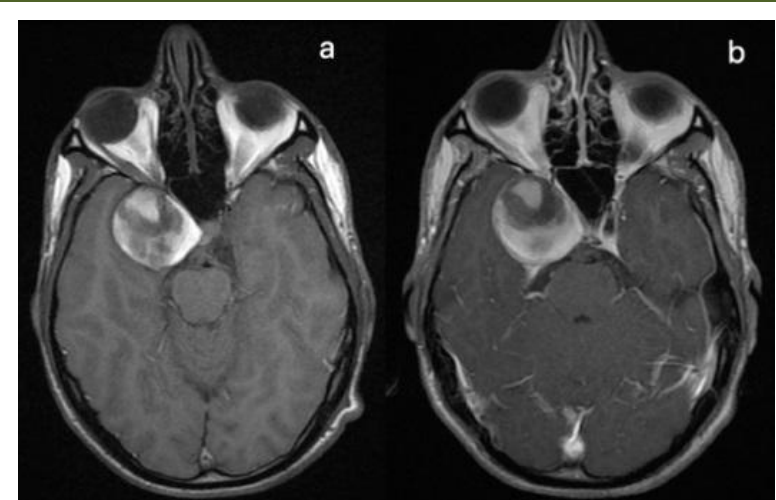

Fig-2: $T_{1}$ weighted MRI, axial slices before (a) and after gadolinium injection (b), Right intracavernous heterogenous masse partially enhanced after gadolinium

\section{DISCUSSION}

Intracavernous carotid aneurysm should be isolated from the other intracranial aneurysms, not only because of their frequency among the giant aneurysms, but also because of their natural history, clinical symptomatology, and treatment.

The etiology of giant aneurysms is multifactorial and many structural and hemodynamic stress factors have been previously discussed. Idiopathic intracavernous aneurysms are the most common [4], however the frequency of bilateral intracavernous aneurysms have definite causative factors suggesting weakness of the carotid arterial wall. They can occur after radiation therapy, or in association with connective tissue disorders such as fibro- muscular dysplasia and Paget's disease. Furthermore, infectious (mycotic and bacterial) intracavernous aneurysms have been reported in the past [5].

The intracavernous part of the internal carotid artery (ICA) extends from the superior part of the petrolingual ligament to the proximal dural ring. The ICA enters the posterolateral angle of the cavernous sinus and makes a medial curve. It narrows the 3 rd cranial nerve (III), the 1 st part of the 5 th cranial nerve (V1), the 4th (IV) and the 6th (VI) cranial nerves. The neck of the aneurysm may be located in variable locations of the intracavernous part of the ICA, causing the compression of the lateral wall of cavernous sinus by the entire aneurysm [6].

The likelihood of an aneurysm becoming symptomatic is directly related to its size. Small aneurysms are primarily non symptomatic, whereas only $20 \%$ of the giant ICCA are non-symptomatic [7]. Mostly, a progressive onset of the symptoms is observed, with pseudo-tumoral progression, not only due to the compression of the cavernous sinus content by the volume of the aneurysm, but also by the pulsatility of the aneurysmal wall [8]. The most common presenting symptoms in patients with giant cavernous carotid aneurysms $(>25 \mathrm{~mm})$ are diplopia, retro-orbital pain, headache, diminished or blurred vision, and photophobia. Other clinical signs include ptosis, decreased visual acuity, proptosis, and visual field defects [9]. Rarely, an intracavernous aneurysm can present as hypothalamo-pituitary axis dysfunction when it extends into the sellar region [10]. Such aneurysms extending into sellar region account for 1 $2 \%$ of all intracranial aneurysms [11].

Intracavernous sinus aneurysms are thought to have a benign course. However, rare but serious complications include acute partial aneurysm thrombosis, intracavernous aneurysmal rupture leading to a carotid cavernous fistula, and exceptionally massive epistaxis due to a rupture in the sphenoidal sinus [12]. Rarely meningeal hemorrhage and endocrinological manifestations can occur justifying surgical treatment.

Recent advances in imaging techniques, including multidetector row computed tomography, high-field magnetic resonance imaging (MRI), and three-dimensional rotational catheter angiography, have enabled more accurate diagnosis of cerebral aneurysms. However, it is still difficult to visualize the relationship of an aneurysm to the adjacent structures, especially the proximal and distal dural ring, anterior clinoid process, and optic strut [13].

Radiological explorations required for the giant ICCA are identical to the other giant aneurysm locations. Nevertheless, MRI is important for decisionmaking prior to treatment, and is useful for the follow up. T2 weighted coronal views are used to assess the intracavernous location of the aneurysm, eliminating transitional aneurysms with risk of subarachnoid hemorrhage; T1 and T2 weighted views show the anatomical relations of the aneurysm with the wall of the sphenoidal sinus. After treatment, MRI is useful to verify the aneurysmal thrombosis and the shrinking of the aneurysm.

Optimal management of symptomatic giant carotid aneurysms remains controversial. The indication to treat is difficult because the natural history of the giant ICCA is uncertain, particularly it is known that spontaneous recover of the clinical symptoms (mainly oculomotor deficits) may sometimes occur. In the literature, a trend seems to appear regarding the main factors in the treatment of giant ICCA, the importance of clinical disability, evolution of the symptoms, and development of the MRI findings which should all be considered prior to any decision making[8].

Nowadays direct surgical approach is exceptionally proposed for giant ICCA because of its invasiveness, its morbidity and mortality, and because of the technical difficulties to achieve a satisfying aneurysmal occlusion $[8,14]$. The endovascular procedures have considerably modified the treatment strategy [15]. 


\section{Conclusion}

Intracavernous carotid artery aneurysm is a relatively rare disorder with benign courses. However giant ICCA can present as serious complications which may lead to life-threatening consequences. Recent advances in imaging techniques, especially magnetic resonance imaging have allowed for earlier diagnosis of intracavernous aneurysms before complications appearing.

\section{REFERENCES}

1. Purvin VA. Neuro-ophthalmic aspects of aneurysms. International ophthalmology clinics. 2009 Jul 1;49(3):119-32.

2. Perez de Vasconcellos L, Flores JAC, Veiga JCE, Conti MLM, Shiozawa P. Presentation and treatment of Carotid Cavernous aneurysms. A rq Neuropsiquiatr. 2008;66(2-A):189-193

3. Penchet G, Mourier K. Collaborative retrospective multicentre series of giant intracavernous carotid aneurysms. Neurochirurgie. 61(2015): 366-370

4. Sekhar LN, Ramanathan D, Hallam DK, Ghodke $\mathrm{BV}$, Kim LJ. What is the correct approach to aneurysm management in 2011?. World neurosurgery. 2011;75(3-4):409-11.

5. Caroli M, Bertani G, Fetoni V, Sasanelli F, Gaini SM, Samis MZ. Bilateral intracavernous carotid artery aneurysms presenting as abducens nerve palsy: case report. Journal of neurosurgical sciences. 2009 Dec;53(4):169-70.

6. Kim JM, Romano A, Sanan A, van Loveren HR, Keller JT. Microsurgical anatomic features and nomenclature of the paraclinoid region. Neurosurgery. 2000; 46:670-80, discussion 80-2.
7. Oldenberg-Cohen N, Curry C, Miller NR, Tamargo RJ, Murphy KP. Long term visual and neurological prognosis in patients with treated and untreated cavernous sinus aneurysms. J Neurol Neurosurg Psychiatry. 2004;75:863-7.

8. Eddleman CS, Hurley MC, Bendok BR, Batjer HH. Cavernous carotid aneurysms: to treat or not to treat? Neurosurg Focus. 2009;26:E4.

9. Hahn CD, Nicolle DA, Lownie SP, Drake CG. Giant cavernous carotid aneurysms: clinical presentation in fifty-seven cases. Journal of Neuro Ophthalmology. 2000 Dec 1;20(4):253-8.

10. Wijethunga WM, Dissanayake HA, Perera S, Katulanda P. Intra cavernous aneurysm of internal carotid artery masquerading as a pituitary adenoma: a case report. BMC research notes. 2018 Dec;11(1):237.

11. Heshmati HM and al. Hypopituitarism caused by intrasellar aneurysms. Mayo Clin Proc. 2001;76(8):789-93.

12. Van der Schaaf IC, Brilstra EH, Buskens E, Rinkel GJ. Endovascular treatment of aneurysms in the cavernous sinus: a systematic review on balloon occlusion of the parent vessel and embolization with coils. Stroke. 2002; 33:313-8.

13. Inoue S, Hosoda K, Fujita A, Ohno Y, Fujii M, Sugimura K, Kohmura E. Utility of 320-detector row CT for diagnosis and therapeutic strategy for paraclinoid and intracavernous aneurysms. Acta neurochirurgica. 2014 Mar 1;156(3):505-14.

14. Ponce FA, Albuquerque FC, McDougall CG, Han PP, Zabramski JM, Spetzler RF. Combined endovascular and microsurgical management of giant and complex unruptured aneurysms. Neurosurg Focus. 2004; 17:E11. 